\title{
A AUTONOMIA CERCEADA DA ESCOLA PÚBLICA, DIANTE DAS INTENÇÕES “NÃO DECLARADAS” DO ESTADO (1995-1998)
}

\author{
Valéria Moreira Rezende ${ }^{1}$ \\ Universidade Federal de Uberlândia - UFU \\ valeria@pontal.ufu.br \\ Financiamento: FAPEMIG
}

\section{RESUMO:}

Este trabalho procura analisar numa perspectiva político-educacional e mediante a análise de processos de prestação de contas selecionados, as formas de gestão dos recursos financeiros feita pelas escolas, proveniente da reforma educacional decorrente do Programa de Descentralização proposto pelo governo mineiro no período de 1995 a 1998. Procurou-se verificar em que medida as escolas tiveram autonomia para gerir seus recursos de acordo com suas necessidades. Verificou-se também como instâncias superiores lidavam com esta questão na perspectiva da ampliação/tolhimento da autonomia das escolas. Concluiu-se que há uma inversão: contradizendo a política da reforma proposta, a autonomia da escola não se efetiva na prática. As autoridades superiores se sobrepõem à autonomia anunciada, caracterizando uma desconcentração de tarefas, sem atribuir poder de decisão às escolas. As formas de repasse e de controle dos recursos financeiros constitui-se em processo arbitrário, pouco contribuindo para o favorecimento da autonomia escolar. São empenhados mecanismos de controle que expressam uma política altamente centralizadora sob a capa da descentralização. Por outro lado, as escolas usam de subterfúgios, para burlar o imperativo da norma e exercer a autonomia possível.

Palavras-chave: Política educacional - Autonomia da escola descentralização/desconcentração - financiamento.

\section{CUTTING SHORT PUBLIC SCHOOL AUTONOMY FACING "UNDECLARED" STATE INTENTIONS (1995-1998)}

\section{ABSTRACT:}

This paper tries to analyze, in a political-educational perspective and through the examination of selected accounting processes, the school's management of financial resources provided by the educational reform originated from the 1995-1998 Decentralization Program proposed by the Minas Gerais State government. The author tries to verify the limits of school's autonomy in managing their resources according to their necessities, and how superior echelons deal with that question, in the perspective of school's autonomy widening/obstructing. The conclusion is that there is an inversion: contradicting the proposed reform policy, school's autonomy does not actually become effective. High rank authorities overpower the alleged autonomy, characterizing task dispersion, without crediting decision power to schools. Financial resources dispensing and controlling is an arbitrary process that very little favors school's autonomy. Control mechanisms involved express a highly centralizing policy disguised as decentralization. Schools, on the other hand, use subterfuges to bypass legal imperatives and exercise the possible autonomy.

Keywords: educational policy; school autonomy; decentralization/dispersion; funding 


\section{1- Introdução}

Os estudos que analisaram as políticas de descentralização ocorridas na década de 90 na América Latina tiveram como um eixo central de discussão, as questões da relação descentralização x desconcentração e da autonomia da escola.

Esse panorama foi marcado por profundas mudanças na configuração de diversos países, inclusive o Brasil, no que tange às políticas sociais. Conforme afirma Costa (1997), embora a gestão democrática da educação brasileira fosse consagrada como norma jurídica desde a Constituição Federal de 1988, sua regulamentação tem sugerido uma diversidade de interpretações no âmbito dos estados brasileiros. A década de 90 apresentou-se como um momento ímpar na formulação das propostas no campo educacional, e mais especificamente da gestão da educação, em torno de preocupações com objetivos, meios e fins que a educação pública deve atender (Costa: 1997, p.23).

Segundo o discurso oficial, as reformas educacionais, nas diferentes esferas de governo do Brasil, têm buscado desenvolver, especialmente com a descentralização, meios mais democráticos de gestão. Segundo esta ótica, as mudanças, nessa área, têm sido influenciadas pelo movimento de globalização das economias mundiais e pela exacerbada ingerência do neoliberalismo que estimula a competitividade na busca de mais eficiência e melhor qualidade da educação pública, exigências que levaram o Estado brasileiro a redefinir seu papel e a moldá-lo conforme as necessidades exigidas e equiparadas às leis de mercado.

Diante deste quadro não há como pensar a educação isolada do próprio contexto sócio-político e econômico, o que supõe duas questões: até que ponto a escola tem autonomia ou se rende à submissão? Em outras palavras, em que medida a educação é afetada por este contexto e em que medida ela possui autonomia perante as transformações e oscilações políticas e sociais? Identificar essa desafiante realidade é uma tarefa árdua e contínua de pesquisadores ligados à educação e preocupados com o futuro da educação brasileira.

\section{2- Fatores que impulsionaram a descentralização}

Casassus (1995) aponta que o processo de descentralização foi impulsionado por fatores decorrentes da insatisfação dos governos anteriormente centralizados, que se sentiam limitados frente às novas exigências dos sistemas de ensino.

O primeiro fator relacionar-se-ia com o efeito democratizante que se espera das políticas educacionais pois, apesar de favorecido o acesso à escola, o esforço empregado não foi suficiente para compensar as desigualdades sociais, pois a qualidade da educação oferecida distribuiu-se de forma acentuadamente irregular. Outro fator seria consequiência da crise no financiamento da educação: de um lado, exige-se mais educação, o que implica aumentar o número de anos de permanência no sistema escolar formal; mas esta aspiração é limitada, em parte, porque exige maior disponibilidade de recursos financeiros, justamente num período de ajustes estruturais e de crise financeira. E um terceiro fator de insatisfação resultaria da ineficácia da capacidade de gestão do sistema burocrático, criado para atender as necessidades da expansão educacional. Dois aspectos sobre esse ponto devem ser considerados: o tamanho do sistema educacional e a concentração de poder político.

Com a expansão do sistema educacional, surgem estruturas administrativas de grandes proporções, operacionalmente obsoletas e comumente arcaicas em relação às 
exigências da modernização. $\mathrm{O}$ fenômeno torna-se mais complexo onde as estruturas burocráticas são consideradas mais numerosas e onde a multiplicidade de regulamentações é maior. Face à acumulação destes dispositivos cada vez mais impessoais e "desumanos", o fator humano passa a defender-se desses mesmos dispositivos, retraindo-se.

A administração do sistema educacional age por meio da centralização das decisões em nível "macro", de modo que as políticas educacionais são elaboradas por técnicos vinculados à estrutura do poder central. Historicamente, o poder no setor educacional localiza-se nos altos escalões, constituindo-se numa superestrutura que traz em seu interior forte conteúdo de conflitos de natureza política. Nesse jogo de interesses, acomodação de conflitos e lutas de poder, onde uns ganham e outros perdem, uns apóiam e outros rejeitam a trama dominante, não se leva em conta, na maioria das vezes, o fim principal de toda essa negociação — o aluno (Casassus: 1995, p.45).

A própria lógica do sistema burocrático em um Estado centralizado tende a situar e legitimar a autoridade no topo do sistema, outorgando-lhe o direito de decisão e de regulamentação em áreas substantivas, administrativas e de alocação de recursos para o conjunto do sistema. Assim, por um lado, os ministérios de educação normalmente apresentam um panorama de estruturas altamente hierarquizadas, onde a dinâmica de gerenciamento e um vasto conjunto de decisões tendem a concentrar-se (às vezes até a saturação) em torno de um ministro ou secretário de Educação e o seu gabinete. Por outro, na medida em que a autoridade é designada pelo poder executivo, o exercício do poder institucional caracteriza-se por uma acentuada dimensão política. Esta combinação constitui uma capacidade maior de impor uma ação. Entretanto, na prática, observa-se uma alta rotatividade de autoridades, traduzindo-se em uma sequiência de medidas adotadas, as quais anulam-se mutuamente até dentro de um mesmo período governamental (Casassus:1990 p.16).

Deste modo, o autor ainda afirma que a complexidade do sistema educacional, que vem contribuindo para a inviabilização das prioridades educacionais estabelecidas pela implantação de ações consideradas fundamentais para $\mathrm{o}$ atendimento às questões educacionais no país, recomenda como estratégia básica a descentralização dos sistemas de ensino, por meio de órgãos regionais e da criação de outras instâncias em nível da sociedade local e da escola. Isso ampliaria, pelo menos em termos, as possibilidades de intervenção da comunidade escolar, na discussão, elaboração e execução dos planejamentos educacionais.

\section{3- Descentralização e desconcentração}

Para entender as políticas de descentralização como proposta de reforma educacional, é preciso detalhar os conceitos de centralização, desconcentração e descentralização, apresentados pelos autores que abordaram o tema. Quando tais conceitos entrecruzam-se, é possível olhar as políticas educacionais de diferentes modos.

Rivas (1991), quando descreve o "estado da arte" das políticas de descentralização na América Latina, identifica duas lógicas distintas nas principais políticas educacionais que estudou: uma de caráter neoliberal, ou liberal economicista, e outra crítica, ou democrático-participativa. Ambas têm em comum, ao visar à descentralização, a delegação de maior poder à unidade local, buscando mais eficiência administrativa, racionalização de recursos e também um currículo mais afinado com as particularidades regionais. $\mathrm{O}$ autor 
destaca três formas de execução da política educacional: a centralização, a desconcentração e a descentralização.

A centralização ocorre quando as decisões públicas e administrativas são adotadas por um centro de poder do Estado que concentra as decisões diversas do setor educacional.

A desconcentração, ou o descongestionamento do órgão central, acontece por meio da distribuição de tarefas para os órgãos locais, mantendo ainda concentrado o poder de decisão.

Por desconcentração se entende o sistema em que o Estado Central delega determinadas funções a entidades regionais ou locais que depende diretamente do órgão central que mantém concentrado em seu poder a tomada de decisões e o direito para outorgar modificar ou retirar atribuições dos funcionários dessas repartições ou simplesmente removêlos (Rivas: 1991, p. 20).

A descentralização propriamente dita dá-se quando se transfere poder de decisão e autoridade com o objetivo de fortalecer a escola, criando um processo de democratização da educação e objetivando o controle das atividades da educação pública pelos agentes que estão diretamente envolvidos. Ou seja:

Por descentralização se entende aquela situação em que as diversas entidades regionais ou locais (de governo ou corporações autônomas) com graus significativos de autonomia, definem as formas próprias em que se deve organizar e administrar o sistema de educação pública em suas respectivas áreas. $\mathrm{Na}$ descentralização não há somente uma delegação de faculdades operacionais, há também o exercício do poder de decisão real sobre os aspectos importantes no maneja financeiro, a elaboração do currículo local e a administração e gestão educacionais em zonas geográficas determinadas (Rivas:1991, p.20).

Se, por um lado, essas reformas enxergam a descentralização como uma das principais saídas, para resolver a crise, por outro lado não podem ser vistas como uma solução mágica que de uma hora para outra resolveria todos os problemas cristalizados sob a égide do centralismo desde o Brasil Colônia.

Apresentar a descentralização de forma mítica só serve para entravar ainda mais o processo de mudança. A este tipo de postura pode-se associar outra que imprime uma utilização política à luta pela descentralização. Neste caso, também é supervalorizado o poder da descentralização para resolver os males estruturais do Estado. A utilização política, em tais circunstâncias, serve para encobrir responsabilidades de determinadas agências governamentais que, ao não cumpri-las, culpam a centralização pelo mau desempenho de suas obrigações (Lobo: 1990, p.6).

É consenso entre os autores afirmar que a descentralização tem o objetivo de melhorar os sistemas de ensino como superação das limitações dos sistemas centralizados e burocráticos e em consequiência proporcionar uma maior fluidez nas atividades executadas pelas instâncias regionais ou locais e melhoria na qualidade da educação.

Rivas (1991) mostra que os países da América Latina, ao se envolverem no processo de descentralização, estabeleceram três objetivos como meta: melhorar a 
eficiência e modernizar os sistemas educativos, para romper a tradicional estrutura centralizada e burocrática e conseguir participação efetiva das unidades locais no uso dos recursos de maneira descentralizada; melhorar a gestão participativa mediante a incorporação de mais atores sociais nos processos de decisão, para romper $\mathrm{o}$ distanciamento da escola e da comunidade; e aumentar a efetividade do sistema, para adaptar o currículo as necessidades e culturas locais.

Lobo (1990) categoriza como objetivos da descentralização aprimorar as relações intergovernamentais, capacitar melhor os governos subnacionais para a função de agentes interventores de suas realidades e possibilitar o controle sobre a ação do poder público.

Casassus (1995) aponta que os objetivos da descentralização vinculam-se à lógica dos acréscimos: a) mais democracia, ou possibilidade de participação e maior espaço para a diversidade; b) mais recursos, ou interesse da sociedade civil em participar da do financiamento; c) mais eficiência, ou desburocratização dos sistemas centralizados.

A descentralização na educação passaria pela necessidade de romper com os modelos centralizados, visto que, teoricamente, a descentralização educacional estaria intrinsecamente ligada à participação mais efetiva das unidades descentralizadas, à melhor aplicação dos recursos, ao descongestionamento burocrático dos modelos anteriormente centralizados e, portanto, à racionalidade da máquina administrativa. Aparece determinada a alcançar metas relacionadas ao desenvolvimento da qualidade da educação e a eficiência e eficácia do sistema de ensino. No entanto, a efetividade desse processo não se dá de forma linear. Os aspectos políticos interferem diretamente no processo, condicionados pelos governos que apresentam a descentralização conforme seus interesses. Os mecanismos utilizados por esses governos para repassar recursos que efetivam a descentralização também é alvo dessas influências. Por fim, o aspecto administrativo é um dos maiores pontos de resistência à descentralização, quando os governos controlam a tomada de decisões e não abrem mão do poder que exercem.

\section{4- Descentralização e autonomia}

As políticas de descentralização que visam à racionalização dos sistemas educacionais, mediante o repasse de recursos financeiros e a administração participativa como subsídios das ações pedagógico-educacionais, apresentam como veio norteador a autonomia da escola e, em conseqüência, a constituição de novas funções na escola que supostamente teria ampliado o seu poder de decisão. Os governos têm enfatizado este discurso, que não é ingênuo. A constituição da escola autônoma é complexa e, segundo Salles (1992, p.57), quando analisa a autonomia da educação, a ideologia da educação passa pela lógica neoliberal e foi construída como instrumento de equalização social, "porque sempre souberam com habilidade acentuar o papel autônomo e independente do processo educacional". Este autor adverte:

A simples observação da experiência cotidiana demonstra fartamente a falácia dessa autonomia: planos interrompidos, programa de construções reduzidas, impostas por variadas razões restritivas, falhas no alcance dos objetivos declarados, compõem a rotina monótona que inegavelmente depõe contra a defesa de uma autonomia irrestrita do sistema escolar (Salles: 1992, p.50).

Completando essa idéia, Salles (1992, p.51) alega ainda que "a educação realiza-se nas sociedades capitalistas, muito mais pelas intenções não declaradas do que propriamente 
pelas que são expressamente declaradas". Essa contradição entre o proclamado e o realizado contradiz a própria idéia de que a educação desempenha um papel de equalizador social.

As intenções declaradas pelos governos, quando implantam o modelo de descentralização nos seus sistemas de ensino, se traduzem em atribuir autonomia às escolas, por meio de maior participação nas decisões e de gestão dos recursos humanos, administrativos e financeiros; foi então o caminho indicado para as instituições escolares. Assim, a autonomia deixaria de ser simplesmente um slogan, para se transformar em uma outorga de poder que daria competência para definir a renovação educacional. Esta tem sido a tônica dos discursos políticos que se propõem a descentralizar os seus sistemas educacionais.

Nesse sentido, a autonomia exigiria uma profunda revisão e, com esta, o surgimento de novas funções e papéis na escola, para dar-lhe poder e governabilidade. Desta forma, não caberia à administração pública central e regional fazer opções pedagógicas, administrativas e financeiras, mas permanecer "em aberto", para não definir e abafar as decisões; isto é, o pluralismo de idéias só se efetivaria se a escola tivesse autonomia de decisão e iniciativa para redimensionar sua prática, resultante da reflexão de todos os segmentos da escola e da comunidade. A autonomia que a escola requer, como condição indispensável de sucesso - maior grau de decisão sobre a aplicação dos recursos financeiros, porque nenhuma instituição pode ter identidade, iniciativa e projeto se não detiver o controle sobre seus próprios recursos — seria concretizada por meio da descentralização.

Por outro lado, a participação efetiva na educação, como rompimento da ordenação autoritária no período do centralismo, surge como uma ânsia na qual têm se congregado os diversos setores da educação. Porém, transferir responsabilidades para as unidades escolares não garante a maior participação de seus membros. A simples administração local não representa por si só sua efetiva democratização nem a conquista da gestão autônoma. Ao contrário, pode significar o aumento do controle dessas unidades e o tolhimento do seu poder decisório.

Quando as intenções não declaradas se manifestam, a descentralização que deveria proporcionar a autonomia aparece ainda com outra roupagem, apenas transferindo responsabilidades e tarefas, sem delegar poder de decisão e atendo-se ao campo administrativo, sem envolvimento com o campo político. Esta outra modalidade de descentralização é definida como desconcentração, conforme já visto. A autonomia da escola deixa de ser concreta e passa a ser ambígua, o que "acaba abrigando significados contrários" (Azanha: 1995, p.146).

Quando discute a melhoria da qualidade do ensino e a autonomia, Azanha (1995) propõe um possível caminho para a autonomia da escola. Ele considera que, em primeiro lugar, ninguém poderá fazer pela escola "aquilo que somente ela pode fazer" (Azanha: 1995, p.24). Determinações superiores, que ditam normas e planejam a melhoria da qualidade do ensino sem considerar a sua realidade, não concretizam a sua autonomia. Para tanto, é preciso que a escola seja provida de condições e recursos para que elas possam melhorar. Ele observa que a administração central (e regional) não pensa assim, pois julga que a melhoria do ensino passa estritamente por uma modernização de tecnologia de ensino. Quanto ao plano de melhoria da escola, tem que ser um plano da própria escola. "Há escolas que conseguem organizar seu próprio plano de ensino que passa às vezes por providencias não pedagógicas, mas puramente materiais e físicas" (Azanha:1995, p.25). E mais: 
A autonomia escolar não será uma situação efetiva se a própria escola não assumir compromissos com a tarefa educativa; com relação a esse ponto é preciso lembrar, insistentemente, que o destino das reformas de ensino é decidido no interior das salas de aula (Azanha: 1995, p.144).

Desse modo, para o autor, cada escola deveria ter autonomia de falto para elaborar seu projeto político pedagógico, pois a escola não significa um prédio, um espaço físico ou local, mas escola e governo deveriam elaborar em parceira as políticas educacionais. É preciso que, ao estabelecer um novo modelo de governo, sejam indicados quais os problemas reais que se pretende resolver e que sejam declarados os objetivos reais a que se propõe o processo de descentralização. Sem isso, a descentralização se transforma em retórica vazia e pode até ensejar fortes prejuízos à causa educacional.

Quando as situações não declaradas se manifestam, é preciso considerar que, ao discutir a autonomia da escola, evidenciam-se limites de toda ordem que "deveriam ser removidos ou readequados" (Bassi: 1996, p.42). Quanto aos aspectos administrativos e financeiros, a autonomia da escola vê-se atada a uma severa legislação que se concretiza por meio de normas, leis, decretos e sanções que sufocam a autonomia de qualquer instituição. A legislação controla desde a esfera federal até a municipal e, portanto, "amarra a unidade escolar" (Bassi: 1996, p.44). O repasse de recursos anunciado como fator de viabilidade da descentralização gera limites que se contrapõem à autonomia da escola. Nesse caso, a descentralização que busca a racionalidade e o descongestionamento dos órgãos centrais e regionais acaba enfrentando os interesses da burocracia.

Azanha (1995) chama a atenção para o risco que se corre de transformar a autonomia em complicado processo de burocratização da escola. Sabe-se que o novo sempre amedronta, mas a visão clara de que a autonomia é algo muito sério e depende da cooperação conjunta:

[...] é preciso uma clara consciência, por parte da Administração Estadual, de que a autonomia não é algo a ser implantado, mas, sim, a ser assumido pela própria escola. Não se pode confundir ou permitir que se confunda a autonomia da Escola com apenas a criação de determinadas condições administrativas e financeiras (Azanha, 1995, p.144).

Nesse contexto, autonomia é incompatível com burocratização centralizada e verticalizada do sistema. Os ordenamentos e controles centrais e regionais, tais como vêm sendo praticados, dificultam a construção do projeto institucional pela escola. A autonomia implica liberdade para decidir e agir, implica possuir recursos financeiros disponíveis para a implantação dos projetos e demais atividades atinentes às suas funções e alocação de recursos físicos que propiciem a existência de instalações, equipamentos e materiais adequados, garantindo a sua manutenção; implica, sobretudo, o compromisso das escolas com boa qualidade nas relações e na busca do conhecimento.

Com isso, é necessário enfatizar que a escola pode e deve ser autônoma, mas não independente, já que faz parte de um sistema de ensino, ao qual está integrada: não se defende a idéia de que a escola independa da ação do governo e das instâncias central e regional a que se interliga. A autonomia da escola não descaracteriza o sentido de unidade. Não existe um poder que, com referência às localidades, esteja em posição de real independência com relação ao Estado.

Não se dispensa, entretanto, a atuação do Estado nem das instâncias central e regional da administração, que se considera imprescindível às diretrizes centrais básicas, comuns e também flexíveis. Essas diretrizes seriam reduzidas ao mínimo indispensável, 
abrindo espaço para que a escola construísse seu próprio plano institucional com o objetivo de promover a melhoria qualitativa do ensino.

\section{5- O Programa de Reforma Educacional mineiro e a autonomia da escola}

O governo mineiro na gestão de Eduardo Azeredo (1995-1998) anunciava um programa de melhoria da qualidade do ensino, com o objetivo de eliminar o fracasso escolar, isto é, reduzir os índices de evasão e repetência interpretados como indicadores de ineficiência do sistema. Embora o gerenciamento da escola tenha sido o locus preferencial, o programa, segundo seus proponentes, abrangia a gestão do sistema como um todo.

A idéia repassada à população mineira era a de que estas medidas de fato respondiam às necessidades manifestas por essa população e que era preciso assegurar que se realizassem por meio da utilização de estratégias adequadas e com o gerenciamento adequado dos recursos públicos.

Esse Programa de Descentralização possuía três vertentes: pedagógica, administrativa e financeira. Como essa reforma tinha por princípios renunciar aos antigos hábitos, em que o poder central cerceava a responsabilidade de administração do erário público, essa tomada de decisão, aos olhos do legislador, aparece como um gesto importante e significativo.

Desta forma, "os recursos que antes eram centralizados nas mãos do governo e da burocracia e atendiam as conveniências do clientelismo, passam a ser geridos nas mãos de seus usuários diretos, os próprios dirigentes das escolas" (Guia Neto: 1997, p.107). Sendo assim, com a reforma educativa, segundo a concepção dos legisladores, a escola passa de agente passivo para agente ativo, na medida em que as decisões passam a ser tomadas pelas próprias escolas por meio de ação colegiada. Portanto, o governo optou por atribuir autonomia à escola para que ela pudesse ser vista como escola da comunidade e não como escola do Governo.

A função das Superintendências Regionais de Ensino (SRE), como instâncias intermediárias entre a Secretaria de Estado da Educação de Minas Gerais (SEE/MG) e as escolas, de acordo com esse novo modelo de democratização e descentralização proposto pela Secretaria, seria o de assessorar e apoiar as escolas e não mais tutelar, de forma que lhes fosse assegurada a autonomia pedagógica, administrativa e financeira, como mecanismo de gestão democrática na escola

Um dos focos da descentralização deu-se no âmbito da aplicação dos recursos financeiros, por meio de repasses de recursos originários de diversas fontes, pelos órgãos centrais (SEE/MG e União) diretamente para a escola, ficando a instância intermediária (SRE) responsável pelo monitoramento e assessoramento desse processo.

$\mathrm{O}$ discurso da SEE/MG quanto à gestão financeira das escolas, no que concerne à aplicação dos recursos, assim se desenvolvia:

Os recursos podem ser utilizados pelas escolas conforme as suas necessidades, desde que os gastos sejam aprovados pelo Colegiado que representa a comunidade escolar. A escola estabelece suas prioridades e planeja seus gastos com total liberdade, dentro dos princípios de moralidade, probidade e transparência (Minas Gerais, Secretaria de Estado da Educação, Programa de Capacitação de Dirigentes das Escolas Públicas de Minas Gerais [Procad], Módulo 4: A gestão do pedagógico, Belo Horizonte: 1998, p. 29). 
O que se põe em questão é se os procedimentos adotados para o acesso e o conhecimento dos aspectos legais, inerentes à regular aplicação dos recursos financeiros e a posterior prestação de contas eficiente - favorece de fato a autonomia da escola. Ou seja: em que medida funcionavam os critérios adotados para o repasse de recursos, tendo em vista a alegação de que o que se pretendia era ampliar a autonomia pedagógica, administrativa e financeira da escola da ótica da prática.

Os processos de prestação de contas dos recursos recebidos, fonte primária da pesquisa, permitiram analisar os mecanismos da descentralização e sua relação com a autonomia da escola. Os processos — as janelas que franquearam essa entrada possibilitaram observar a polêmica, condicionada pela ação da Secretaria, em que se envolvem a Superintendência e a unidade escolar.

\section{6- Da autonomia anunciada à autonomia "controlada": dois pesos e duas medidas}

A gestão dos recursos financeiros pelas escolas constitui-se no recebimento dos repasses, os gastos efetuados e a prestação de contas por meio da montagem dos processos, subordinam-se à hierarquia: Secretaria de Estado de Minas Gerais - SEE/MG e Superintendência Regional de Ensino - SRE

A aplicação de recursos para a manutenção e aparelhamento das escolas, de origem federal ou estadual, se classifica em despesas correntes e despesas de capital ${ }^{2}$, categorização que deve ser observada pelos presidentes das Caixas Escolares quando o repasse é feito, pois se destina, como já foi especificado, à compra de materiais permanente e de consumo ${ }^{3}$.

Os processos, resultantes da utilização dos recursos financeiros, são fonte significativa de analise para compreensão desse movimento político vivenciado pelas escolas. Eles anunciavam uma dicotomia entre o proposto e o realizado.

\section{1- Os processos de prestação de contas}

A Escola "Aristides Mendes", através de sua Caixa Escolar, recebeu o primeiro repasse de manutenção em 1998, denominado CX 198. A Diretora da escola, juntamente com o Colegiado, para a concretização desse repasse, procedeu de acordo com instruções recebidas nos recursos anteriores e executaram o Termo de Compromisso:

[...] essa verba deverá ser utilizada na compra de materiais diversos para a melhor manutenção da escola, [...] compra de um ventilador móvel de parede vertical para a sala dez, um ventilador para a biblioteca e um para a sala dos professores, [...] abrigo com telha e madeira no portão de entrada [...] uma impressora mais rápida HP seiscentos e noventa e dois e que agilize o trabalho da secretaria, dando mais eficiência e qualidade para os trabalhos da secretaria (Processo 1 da escola Aristides Mendes).

Após o gasto do recurso a diretora descreveu as metas e objetivos alcançados e a utilização do recurso de acordo com as necessidades da escola: "Reunimos com o Colegiado, traçamos metas e objetivos para comprar os produtos da mais alta qualidade e de acordo com nossas necessidades" (Processo 1). Esses argumentos expressam a necessidade de aquisição dos bens, para o bom andamento da escola.

Os materiais adquiridos pela Escola foram: materiais de construção, materiais elétricos, tanquinho de lavar roupas, cortadeira de grama, escada, ventiladores de parede, 
rádio gravador, impressora, armários, grade de proteção, portão, proteção de alto-falante, suporte para som, balança, assinatura de revistas, cartucho para impressora, material de limpeza, pagamento de água e esgoto, tecido para uniforme de ajudante de serviços gerais, camisetas para os alunos.

Ao analisar o processo a Superintendência ${ }^{4}$ verificou que os gastos foram, em parte, destinados à aquisição de materiais de construção ${ }^{5}$ e materiais permanentes, ambos adquiridos em grande quantidade, solicitando, então, esclarecimentos à escola, ao mesmo tempo em que pediu aos órgãos centrais da SEE orientações de como proceder, além da aceitação dessas despesas. A resposta deste pedido foi "desfavorável quanto à aquisição do material permanente e de construção pela escola” (Processo 1 - grifo meu).

Após o parecer desfavorável da SEE, a instância intermediária "esclarece" a todos os diretores quanto à utilização dos recursos para manutenção das escolas.

- É vetado à Caixa Escolar e ao Colegiado apesar de sua reconhecida autonomia, o direito de alterar o objeto do Termo de Compromisso ou de descaracterizar a natureza do repasse.

- Considerando que o recurso da Caixa Escolar CX, está classificado na rubrica - Auxilios para Despesa Corrente, salientamos que fica a Caixa Escolar impedida de adquirir material permanente com o referido recurso (Processo1; grifos no documento).

Do ocorrido, três considerações puderam ser destacadas. Em primeiro lugar, quanto ao período de envio desse ofício circular pela SRE às escolas, a Superintendência alerta as escolas, depois de a SEE ter coibido a compra indevida pela Escola "Aristides Mendes".

A mudança de atitude da Superintendência Regional, quando alerta as escolas para que não incorram no mesmo erro, deve-se ao fato de ter recebido o parecer desfavorável da instância central, ela não só acatou a decisão como divulgou a proibição entre todas as unidades a si subordinadas.

Em segundo lugar, nem a Superintendência nem os órgãos centrais levaram em consideração a argumentação da escola de que esses gastos foram efetuados em razão do fato de que os últimos recursos destinados à aquisição de material permanente tinham sido disponibilizados em 1995, isto é, três anos antes.

A terceira consideração aponta para a Superintendência que retoma o discurso da Secretaria quando reafirma que, apesar da reconhecida autonomia da escola, não lhe compete alterar a natureza do objeto. A autonomia da escola concedida pela Secretaria é controlada quando se trata de decidir quanto ao tipo de gastos. Os dados coletados nos processos e em especial do processo da Escola "Aristides Mendes", que apontam para a não regularidade dos repasses, ou o cerceamento da natureza dos mesmos, compromete as escolas no atendimento das necessidades por elas definido. Além do caráter impositivo da Superintendência, verificou-se que havia contradições nas tomadas de decisões.

As escolas adquiriam, até este repasse, bens de natureza permanentes com o recurso de manutenção "sem restrições", inclusive compra de gêneros alimentícios. O respaldo legal veio do comunicado do então secretário da Educação, Walfrido S. dos Mares Guia Neto, publicado no jornal Minas Gerais, que determinava:

Com base no parecer n. ${ }^{\circ}$ 8.253/92 de 05.06.92, da Procuradoria Geral do Estado de Minas Gerais, a Secretaria de Estado da Educação comunica: 1) [...] Os recursos financeiros classificados como subvenção social, recebidos através das Delegacias Regionais de Ensino mediante assinatura de Termo de Compromisso, deverão ser aplicados de acordo 
com as necessidades da escola, podendo inclusive ser destinados à compra de material permanente, mobiliário e equipamentos [grifo meu]. 5) O Colegiado da Escola deverá participar da definição e priorização das despesas a serem realizadas com recursos recebidos pela Caixa Escolar, bem como aprovar as prestações de contas da aplicação dos recursos, conforme o disposto do art. $5^{\circ}$ da Resolução 6.907 de 23 de janeiro de 1992 (Minas Gerais, 27/6/92, p. 25).

Não só esse documento concedia às escolas a possibilidade de compra de bens permanentes, mas também reafirmava o poder do Colegiado Escolar como instância maior nas decisões tomadas pela escola. O conteúdo desse comunicado era do conhecimento dos órgãos superiores, por isso a permissão para efetuar essas despesas. Por circunstâncias objetivas e ocasionais, para atender a necessidades específicas esse documento substituiu "temporariamente" a Lei Orçamentária 4320/64?

Inconformada com a decisão de que deveria devolver o valor gasto "indevidamente", a diretora foi pessoalmente a Belo Horizonte na SEE-MG juntamente com todos os membros do Colegiado, em ônibus fretado, apelar da decisão imposta pelas instâncias regional e central.

Solicitamos de V. Sa., atenção especial às nossas justificativas e defesa lavradas em ata comprovadas e assumidas pela nossa presença aqui em BELO HORIZONTE, com representação de todos os segmentos da comunidade, pois acreditamos estarmos imbuídos numa missão solidária de aprendizagem, compromisso, responsabilidade, crescimento e transformação social (Processo 1).

A decisão da diretora da escola de apelar para o órgão central, de levar o Colegiado à presença dos responsáveis pelo poder, confirma a hipótese de que o poder de decisão está concentrado na Secretaria, não somente quando determina as rubricas dos repasses, define o tempo de gastar e prestar contas, define o objeto do repasse e fiscaliza os gastos, mas ainda quando impede a escola de estabelecer suas prioridades.

A SEE então se posiciona através de suas diretorias e mantém-se rígida em sua decisão, mesmo após o apelo pessoal dos representantes da Escola "Aristides Mendes" e reafirma: "continuamos de parecer desfavorável quanto à aquisição do material permanente e de construção pela escola" (Processo 1; grifo no documento).

Após analisar novamente o processo, a SEE acrescentou alguns itens que tinham sido "poupados" pela instância regional, e a devolução passou de R \$ 3.114,08, para R\$ 4.649,08, com o prazo de 30 dias para a resolução do caso, limitando ainda mais a possibilidade de argumentação da escola. Não foram considerados pela instância central os argumentos dos membros da escola quando em ata justificaram:

estamos sendo obrigados a adquirir esse recurso (da devolução) próprio para não perdermos a verba da merenda escolar que está com o depósito bloqueado por esta pendência. Todos acham um absurdo um funcionário ter que fazer um financiamento para pagar o que já está pago e aprovado por todos e consideram que seus pareceres nessa prestação estão sendo questionados de uma forma que na verdade descaracteriza a AUTONOMIA DO COLEGIADO e da escola (Processo 1). 
Após várias prorrogações do prazo para a devolução pela escola à Secretaria, com os valores corrigidos segundo os índices oficiais predeterminados no valor total de $\mathrm{R} \$$ $5.010,82$.

A ação da Secretaria da Educação mineira diverge do modelo proposto pela política de descentralização. As leis e normas impostas na prática, independente dos argumentos e ações da escola, contradizem a sua proposta

Ao discutir os problemas do dia a dia da escola, o Colegiado tem que considerar [...] as normas emanadas da Secretaria de Estado da Educação. Por outro lado, muitas leis normas e regras que regem o sistema educacional são ainda bem rígidas e obsoletas, não acompanhando as constantes mutações do processo educativo. Isso cria sérios obstáculos para que a autonomia da escola se concretize de fato e para que o seu destino seja verdadeiramente decidido pela comunidade (Minas Gerais, Procad, Módulo 2: A escola pública de qualidade - Pressupostos e fundamentos. Belo Horizonte, 1998, p. 106).

O que se pode verificar de todo esse processo é que em momento algum os argumentos dos órgãos central e regional se voltaram ao mérito da compra. A escola, de alguma forma, procurou justificar a compra em razão de suas necessidades e apoiada em comunicado anterior da Secretaria que permitia a aquisição de tais materiais. As instâncias superiores, mesmo alertadas de que este procedimento havia sido aprovado em momentos anteriores, manteve-se irredutível. Esta irredutibilidade adquire ainda maior significado quando se verifica que, em processos anteriores, de natureza semelhantes, outros foram os procedimentos adotados.

Por outro lado, com o mesmo repasse CX 1/98, a Escola "Carlos Dâmaso", como foi verificado no processo 3, utilizou $\mathrm{R} \$ 950,00$ na compra de uma impressora e ainda anexou ao processo ao ato da prestação de contas uma justificativa, comprovando que a compra foi permitida pelas instâncias superiores.

[...] justifico que esta Caixa Escolar não recebeu recurso específico para o projeto de informatização e que consta nesta unidade de ensino um computador doado pela prefeitura municipal, e precisamos de uma impressora". [...] De acordo com a instruções recebidas na SRE [em concordância com a Diretoria de Prestação de Contas/SEE] poderíamos adquiri-la com o Termo de Compromisso em questão (Processo 3).

E ainda em outro processo analisado, referente ao mesmo recurso CX 1/98, também transparece o deslize da SRE. A Escola"Dionísio Correia de Andrade" aplicou parte do recurso recebido, $\mathrm{R} \$ 1.038,50$, na compra de material permanente: ventiladores e aparelho telefônico. Na diligência encaminhada à Caixa Escolar pelo analista da SRE responsável pelo processo 4, não foi mencionada esta aquisição indevida de bens permanentes. $\mathrm{O}$ processo foi aprovado e arquivado pela Regional.

Os processos das escolas "Aristides Mendes","Carlos Dâmaso" e "Dionísio Correia de Andrade", de igual teor, comprovam uma ações diferençadas pelas instâncias superiores. No caso da Escola“Dionísio Correia de Andrade", o processo 4 foi aprovado sem consulta ou questionamentos, pois a aquisição indevida parece ter passado "desapercebida" pelo analista. No caso da Escola "Carlos Dâmaso", o órgão central foi consultado pela Superintendência, que se manifestou favorável, como mostra o processo, e 
que redundou na aprovação da compra. E no caso da Escola "Aristides Mendes", foi feita a consulta formal ao órgão central, que coibiu a decisão da escola pelos gastos realizados.

Nos processos 7, da Escola "José Borges", e 10, da Escola "Carlos Dâmaso", foi possível verificar também esses deslizes das instâncias superiores quando em análise dos processos agiram contraditoriamente no que tange a legislação.

A Escola "José Borges" ao receber o mesmo recurso CX 1/98, do valor destinado a compra de bens de consumo, adquiriu quatro coleções de livros de alfabetização de $1^{\mathrm{a}}$ a $4^{\mathrm{a}}$ série. A Superintendência não considerou a necessidade da escola em adquirir os livros nem tampouco atribuiu a ela o poder de decidir, prevalecendo o imperativo da norma que prescreve "coleções como material permanente". Portanto, o pedido de devolução pelo analista do processo foi iminente.

Como a Escola "José Borges"não cumpriu com a determinação da SRE, para a regularização da pendência, recebeu uma diligência comunicando que, caso não fosse regularizada a pendência no prazo máximo de 15 dias, o processo seria encaminhado para o Tribunal de Contas do Estado de Minas Gerais, para as providencias cabíveis. Após tentativas sem lograr êxito, não conseguindo que a escola efetuasse a devolução solicitada, a SRE encaminha o processo 10, da Escola "José Borges", à diretoria de Prestação de Contas/SEE, para que esta pudesse exigir da escola o cumprimento da norma. A instância superior, após analisar o processo, devolve-o à instância regional com o "parecer favorável” à escola e determina:

Que seja feita a verificação 'in loco' para identificação da mercadoria adquirida e anexado o relatório de visita ao processo, lembrando que as despesas poderão ser acatadas, estando sujeitas a julgamento pelo órgão concedente caso a mercadoria se encontre na escola (Processo 10; grifo meu).

A SRE, através da inspetora responsável pela escola, fez a verificação in loco, apresentando no relatório que entre outras, continha a seguinte observação: "Confirmamos que as coleções se encontram na Biblioteca da Escola "José Borges"do município de "AB", sendo muito utilizadas pelos professores" (Processo 10; grifo meu).

A Secretaria autoriza a compra das coleções de livros pela Escola "José Borges", desautorizando o poder da instância regional. No entanto, essa autorização não é concedida sem mecanismos de controle, quando impõe a averiguação in loco para confirmar a utilização dos livros.

O procedimento de análise do Processo 7 de prestação de contas da Escola "Carlos Dâmaso", adotado pela instância regional, foi o mesmo adotado pelo processo 10 da Escola "José Borges", embora não tenha tido o mesmo resultado. A Escola "Carlos Dâmaso" adquiriu com o mesmo recurso repassado à Escola "José Borges"quatro coleções de livros da mesma editora e na mesma época. Por esta aquisição, o processo foi diligenciado e a Superintendência pediu a devolução no valor de R \$ 193,00, "referente a gasto indevido de material permanente (Coleções)" (Processo 7). O valor foi devolvido de imediato pela diretora da escola sem questionamentos.

No caso desses dois processos, o que acontece é uma situação em que o órgão central sobrepõe-se à ação da SRE, o que demonstra que a instância regional, mesmo que amparada na legislação, não é levada em consideração.

O que se pode verificar, em relação a esses casos, é a concentração de poder nos órgãos centrais, bem como a absoluta falta de critérios. Por seu lado, as Superintendências 
Regionais, por serem unidades dessa instância maior, não têm autonomia ou poder de decisão e acabam atuando simplesmente como intermediárias das decisões centralizadas.

$\mathrm{Na}$ prática, esta delegação de funções às escolas se caracteriza como desconcentração, sem envolvimento com o poder de decisão e portanto à mercê de decisões superiores e que caracteriza as unidades escolares como "órgãos que não são autônomos que estão sob a dependência direta do poder central” (Rivas: 1991, p.20).

Deste modo, quando se analisa o modelo de descentralização da política educacional mineira, que tem como uma de suas justificativas básicas o repasse financeiro como um dos meios de proporcionar autonomia às escola, o que se verifica, na prática, é o reforço do poder central.

Discutiu-se, neste item, a questão da devolução ou não dos recursos recebidos pelas escolas quando estas os aplicaram indevidamente, de acordo com os regulamentos, quando estas adquiriram material permanente com recursos destinados a compra de bens de consumo. Constatou-se a mais absoluta falta de critérios que redundou em distintas situações:

1) na aprovação direta em um caso, sem que fosse levada em consideração a utilização em material permanente;

2) aprovação de outro, mesmo se verificando que verbas destinadas a material de consumo haviam sido gastas com material permanente;

3) não aprovação e obrigação de devolução de recursos em outro caso, com a justificativa de que verbas destinadas a aquisição de material de consumo foram indevidamente utilizadas na aquisição de bens permanentes;

4) não aprovação do processo e obrigação de devolução do recurso por parte da SRE, sob a alegação de se tratar de compra indevida de material de permanente.

5) não aprovação do processo por parte da SRE e solicitação de devolução do recurso por gasto indevido com material permanente e desautorização da SEE dessa ação, havendo a permissão para a realização da despesa.

Mais sintomáticos ainda são os processos em que os analistas das prestações de contas incorrem em equívocos e procedem diferentemente em cada caso.

Pode-se verificar que o ponto culminante é o problema dos obstáculos institucionais à autonomia da escola que se baseiam nas resoluções que normatizam a vida escolar. Ao longo do tempo, as escolas acabam conseguindo conviver com as normas e, o que é pior ainda, acabam se acostumando com as penalidades, o que dá lugar à legitimação do poder destas instituições superiores. Algumas vezes, no entanto, encontram lacunas que lhes permitem usufruir de iniciativas autônomas. Contudo, contra o poder emissor de normas e determinações, ainda que não sejam legítimas, dos órgãos regionais e central, as escolas pouco podem se opor.

Os elementos evidenciados nestes processos que tratam da gerência dos recursos financeiros pelas escolas mostram que, de um lado, existe a norma e a obrigatoriedade de ser cumprida e, de outro lado, as instâncias superiores, que se contradizem na essência destas prescrições, embora exista a tendência de impor o controle. Os procedimentos dos órgãos administrativos não oferecem parâmetros para que a escola possa se nortear. A incongruência de procedimentos diverge do seu propósito, quando a sua missão deveria ser a de apoiar e assessorar as atividades da escola. Estas instâncias legitimam o poder de autoridade constituída em nome da eficiência, que acaba sendo ideológica, pois não se efetiva na prática de suas ações.

Pelos processos analisados, observa-se que foram definidos parâmetros para uma desconcentração fundada em princípios desarticulados na Política de Reforma mineira, que 
pretendia concretizar uma política de distribuição de recursos e tarefas com a garantia de manter o controle sobre as unidades escolares, modelo incoerente com os ideais de escola democrática alardeada pelos propositores da Reforma.

\section{Considerações finais}

A Secretaria de Estado da Educação de Minas Gerais, para implantar as reformas educativas, conta com o trabalho das instâncias regionais que, com seus setores, departamentos e divisões, têm sob seu comando pessoas que executam funções a serviços da maquina administrativa em nome da eficiência e da racionalidade. Entretanto, ao se verificarem erros cometidos por essas instâncias, são ora corrigidos, ora legitimados e acabam por não criar um padrão estável de conduta que possa servir de parâmetro para as escolas. Esta falta de padrão faz com que as escolas fiquem à mercê das decisões das instâncias superiores, prejudicando e não contribuindo com a sua autonomia.

A lógica dessa ótica atribui à escola uma autonomia contaminada pelo poder superior. Azanha quando fala de autonomia da escola considera que ela não provém de um plano pré-concebido por um órgão supremo que através de modelos estruturados determina a sua competência para a mudança da realidade da escola.

“(...) a autonomia advém do seu próprio interior quando os seus membros se reúnem para examinar sua realidade, levantar suas carências e suas dificuldades e de se organizar para encontrar a solução para seus problemas. Se a própria escola não for capaz de debruçar sobre seus problemas, de fazer aflorar esses problemas e de se organizar para resolve-los, ninguém fará isso por ela". (Azanha, 1995 p. 24)

O poder da autoridade impõe-se sobre os subordinados, usando medidas coercitivas para o cumprimento das normas e leis. (Motta e Pereira, 1986), argumentam que essa relação de autoridade pode consistir tanto na legitimidade de poder do ordenador, como num condicionamento fundado na violência, podendo evidenciar a "autoridade legítima", ou a "autoridade coercitiva", ou seja, o poder legítimo, ou o poder coercitivo.

Lovejoy, citado por Azanha (1995), diz que as palavras tornam-se sagradas quando seus significados assumem sentimentos, crenças e valores em consonância com os gostos de cada época. Neste sentido, as palavras têm o dom de exercer poderes e acabam por impregnar a mentalidade de cada época. Azanha, absorvendo essa idéia para a educação e indo nessa lógica de pensamento, chama a atenção para essas palavras tão corriqueiramente usadas, como autonomia, democratização e participação, descentralização, entre outras. Elas expressam significados marcantes no pensamento e na ação. Palavras como estas, que se tornaram nos últimos tempos bandeiras de discurso políticos e objeto de modismos intelectuais, "condicionam as discussões e a proposição de solução dos problemas educacionais" (Azanha: 1995, p.132). No entanto, esse é um terreno perigoso, afirma o autor, pois ao contrário de expressarem o conteúdo notório que encerram, essas palavras transformam-se em "meros slogans", não tendo nenhuma conotação "mobilizadora" e indicativa de uma direção para a solução dos problemas educacionais. Ou ainda escondem seu verdadeiro propósito, revelando uma idéia imaginaria do que é de fato.

A análise dos processos mostra que todo esse aparato administrativo configura o modelo de organização que incorre numa autonomia controlada, que no dizer de Azanha 
advém da própria estrutura hierárquica dos órgãos superiores que compõem o sistema educacional.

\begin{abstract}
A atual estrutura da Secretaria, foi concebida e implantada para funcionar autocraticamente. Para que se avalie a sua objetividade, é suficiente assinalar o excesso de órgãos centrais e o pletórico elenco de suas atribuições. A permanência desta estrutura é obstáculo intransponível a um autêntico esforço democratizante. Há uma contradição entre uma ação possível a partir da estrutura existente e a verdadeira autonomia da escola (Azanha: 1995, p.143).
\end{abstract}

Parece haver uma contradição: de um lado, a descentralização financeira na educação mineira que vem sendo considerada pelos propositores políticos uma reforma voltada para a racionalização da educação e que, por conseguinte, deveria contribuir significativamente para a melhoria da qualidade, aproximando o processo decisório das necessidades reais, conferindo autoridades às instâncias locais e com isso mais autonomia nas decisões; por outro lado, quando visto na prática, o modelo de descentralização financeira não se concretiza com a proposta que buscava proporcionar "a melhoria da administração educacional e a eliminação de procedimentos burocráticos redundantes, nos níveis estadual e escolar, também propiciaram mais recursos para as escolas" (Martin, Carnoy \& Castro: 1997, p.24). Ao contrário, acentuaram-se os procedimentos burocráticos e as formas de controlar a ação da escola.

A crítica que se faz a essa proposta de descentralização da educação advém justamente da falta de correspondência entre o modelo de descentralização financeira proposto e a realidade política das escolas. A ausência de uma legislação efetiva, que estimule o atendimento das prioridades da escola, concorre para que haja uma pulverização ou uso ineficiente de recursos em projetos não prioritários.

Outra questão a considerar que compromete o efetivo desempenho da atividade pedagógica da escola é quanto às atribuições da escola no cumprimento das tarefas administrativas e financeiras requeridas pelo repasse de verbas. A transferência às escolas de atribuições que antes eram de responsabilidade do poder central, se não for organizada e coerente, pode emperrar o trabalho escolar. As exigências não padronizadas e de caráter puramente formal contidas na administração dos recursos financeiros fazem do diretor um gestor burocrático. Desta forma, como se viu, esses limites jurídicos e a execução de tarefas e normas engessam a ação da escola limitando a realização da sua autonomia.

Os procedimentos dos órgãos administrativos não oferecem parâmetros para que a escola possa se nortear. A incongruência de procedimentos diverge do seu propósito, quando a sua missão deveria ser a de apoiar e assessorar as atividades da escola. Estas instâncias legitimam o poder de autoridade constituída em nome da eficiência, que acaba sendo ideológica, pois não se efetiva na prática de suas ações.

Do ponto de vista da efetiva autonomia da escola pública, o governo do estado de Minas Gerais vem criando sucessivos mecanismos para que as escolas da rede estadual recebam recursos - nem sempre suficientes ou específicos - de forma que possam efetuar sua própria manutenção. Todavia, este repasse de recursos financeiros vem acompanhado de mecanismos de controle que expressam uma política altamente centralizadora sob a capa da descentralização.

Dos processos que foram analisados, foi possível verificar que não só as escolas não gozam de autonomia como é muito forte o controle exercido pelo poder regional e 
central, acentuado pelos ditames burocráticos. Quanto a aplicação dos recursos financeiros, as escolas não têm poder de decisão, ficando submetidas as determinações superiores.

Deste modo, como a análise dos processos mostrou que isto não se deu de maneira uniforme, e que muitas dessas escolas procuraram resistir a imposições que lhes pareceram inadequadas (muitas delas conseguindo reverter situações desfavoráveis), ficou evidente que as formas como se efetivam e se controlam, de fato, os repasses financeiros para gastos pela escola reforça a centralização do poder e não a sua distribuição.

\section{Referências Bibliográficas}

AZANHA, José Mário Pires. Educação: temas polêmicos. São Paulo: Martins Fontes. 1995.

BASSI, Marcos Edgar. Política educacional e descentralização: uma crítica a partir da análise da descentralização financeira dos recursos públicos enviados às escolas no Estado de Minas Gerais. Dissertação de mestrado apresentada à Pontifícia Universidade Católica de São Paulo. 1996

CASASSUS, Juan. "Descentralização e desconcentração educacional na América Latina: fundamentos e críticas". Cadernos de Pesquisa. São Paulo, Fundação Carlos Chagas, no 74, 1990, p. 11-19.

. Tarefas da educação. Campinas: Autores Associados. 1995

COSTA, Vera Lúcia Cabral, org. Gestão educacional e descentralização: novos padrões. São Paulo: Cortez/Fundação para o Desenvolvimento Administrativo (Fundap). 1997

GUIA NETO, Walfrido S. Mares. "A reforma educativa em Minas Gerais". In CARNOY, Martin \& CASTRO, Cláudio de Moura, orgs. Como anda a reforma da educação na América Latina? Rio de Janeiro: Editora Fundação Getúlio Vargas, 1997, p.105-120.

LOBO, Thereza. "Descentralização: uma alternativa de mudança" Revista de Administração Pública. Rio de Janeiro, v. 22, nº 1, 1988 p.12-33.

"Descentralização: conceitos, princípios, prática governamental". Cadernos de Pesquisa. São Paulo, Fundação Carlos Chagas, nº 74, 1990, p. 5-10.

MINAS GERAIS. Secretaria de Estado da Educação. Programa de Capacitação de Dirigentes das Escolas Públicas de Minas Gerais (Procad). Módulo 1: A escola pública de qualidade - O Plano de Desenvolvimento da Escola. Belo Horizonte, 1998.

Programa de Capacitação de Dirigentes das Escolas Públicas de Minas Gerais (Procad). Módulo 4: A gestão do pedagógico. Belo Horizonte, 1998.

Parecer n. ${ }^{\circ}$ 8.253/92 de 05.06.92, da Procuradoria Geral do Estado de Minas Gerais, a Secretaria de Estado da Educação. 1992

RIVAS, Ricardo. Política de descentralización em la educación básica y media en América Latina: estado del arte. Santiago (Chile): United Nations Educational, Scientific and Cultural Organization (Unesco)/Red Latinoamericana de Información en Educación (Reduc). 1991.

SALLES, Fernando Casadei. Descentralização e qualidade de ensino. Dissertação de mestrado em Educação apresentada à Pontifícia Universidade Católica de São Paulo. 1992.

Revista HISTEDBR On-line, Campinas, n.41, p. 146-163, mar2011 - ISSN: 1676-2584 
NOTAS:

${ }^{1}$ Professora da Faculdade de Ciências Integradas do Pontal, da Universidade Federal de Uberlândia - Líder do Grupo de Pesquisa Pólis-Grupo de Estudos e Pesquisas em Políticas, Educação e Cidadania. Doutorado em Educação pela PUC-SP.

${ }^{2}$ De acordo com a lei orçamentária vigente, despesas correntes são aquelas realizadas pela administração pública na execução, manutenção e funcionamento de suas atividades. Isto quer dizer que são despesas correntes a aquisição de materiais de consumo, o pagamento de prestação de serviços de quaisquer natureza, enfim o custeio da maquina administrativa para o seu regular funcionamento. Despesas de capital são as despesas que contribuem para formar um bem de capital, ou adicionar um valor a um bem adquirido. A despesa de capital traz necessariamente a idéia de patrimônio. São investimentos. Material permanente e equipamentos (MINAS GERAIS, Secretaria de Estado da Educação, Manual de orientação às Caixas Escolares para utilização dos recursos financeiros e normas de prestação de contas. Belo Horizonte, 1997, p. 2 e 3

${ }^{3}$ Material permanente é aquele que não perde com o uso sua identidade física. Pela Lei 4.320/64, o material permanente tem duração longa, superior a dois anos. São os equipamentos de computação, de cozinha, máquinas, etc., e o material cívico-educativo, científico, esportivo e recreativo, instrumentos musicais, coleções de livros, fitas gravadas de videocassete, etc. (MINAS GERAIS, Secretaria de Estado da Educação, Manual de orientação às Caixas Escolares para utilização dos recursos financeiros e normas de prestação de contas. Belo Horizonte, 1997, p. 4). Material de consumo é aquele que com o uso perde a identidade física em razão de suas características de deterioração e fragilidade, como: artigos para confecção e vestuário e cozinha; artigos para esportes; materiais de laboratório; artigos para limpeza e higiene materiais para manutenção e conservação de imóveis (cf. Minas Gerais, Secretaria de Estado da Educação, Manual de orientação às Caixas Escolares para utilização dos recursos financeiros e normas de prestação de contas. Belo Horizonte, 1997, p. 2 e 3).

${ }^{4}$ Quando se trata de situar as ações e decisões da instância regional de administração, a SRE, quanto ao processo gasto e prestação de contas dos recursos recebidos pelas escolas, o setor financeiro está à frente de todas as decisões competentes a esse órgão. $\mathrm{O}$ setor pedagógico não aparece, em nenhum dos processos selecionados e nem nos demais pesquisados, para opinar quanto a essas questões. Portanto, nas descrições que se seguem, ao referir-se à essa instância, refere-se ao setor financeiro.

${ }^{5}$ De acordo com as normas da SEE/MG, é permitido adquirir material de construção com o recurso de manutenção apenas para "pequenos reparos", como troca de torneiras, lâmpadas, vidros e outros pequenos serviços. Materiais para reforma do prédio escolar e construção só são permitidos quando a presidente da Caixa apresenta uma planilha de custos à Diretoria de Rede Física/SEE, aprova e libera o repasse específico para esse fim.

Recebido em 09/11/2010

Aprovado em 17/12/2010 